$\begin{array}{cc}\text { ACADEMIA ROMÂNĂ } & \text { Rev. Roum. Chim., } \\ \text { Revue Roumaine de Chimie } & \text { 2019,64(7), 625-631 } \\ \text { http://web.icf.ro/rrch/ } & \text { DOI: 10.33224/rrch.2019.64.7.09 }\end{array}$

\title{
PLURONIC POLYMER CROSSLINKED WITH THIOLENE IN POLYMER DISPERSED LIQUID CRYSTAL FILMS
}

\author{
Farzana AHMAD, ${ }^{\mathrm{a}}$ Kim EUN JEE, ${ }^{\mathrm{a}}$ Muhammad JAMIL ${ }^{\mathrm{b}, \mathrm{c}}$ and Young JAE JEON ${ }^{\mathrm{a},{ }^{*}}$ \\ ${ }^{a}$ LCD Research Center, Department of Chemistry, Konkuk University, Seoul 05029, Korea \\ ${ }^{\mathrm{b}}$ Department of Global Business, Konkuk University, Seoul 05029, Korea \\ ${ }^{\mathrm{c}}$ Department of Physics, Konkuk University, Seoul 05029, Korea
}

In this work, the electro-optical properties of PDLC films based on Thiolene monomer crosslinked with Pluronic polymer are presented. The alteration in flexibility and the solubility of Thiolene matrix in polymer dispersed liquid crystal (PDLC) films in terms of surface morphology, electro-optical variations and changes in glass transition temperatures are investigated. PDLC films were fabricated by polymer induced phase separation (PIPS) method, in which a mixture of thiol-ene- based monomer is crosslinked with Pluronic polymer with different weight ratios. Various properties of resulting PDLC devices have been studied by different experimental techniques. The droplet size variations have been found through scanning electron microscopy (SEM), which exhibited an increase in droplet sizes with the insertion of L31Pluronic ${ }^{\circledR}$. Besides this, it showed a decrease in threshold voltage, increase in the contrast ratio, and a decrease in $\mathrm{T}_{\mathrm{g}}$ with addition of higher contents of L31-polymer. This indicated a weakening in the unbending nature of polymer network with the addition of L-31.
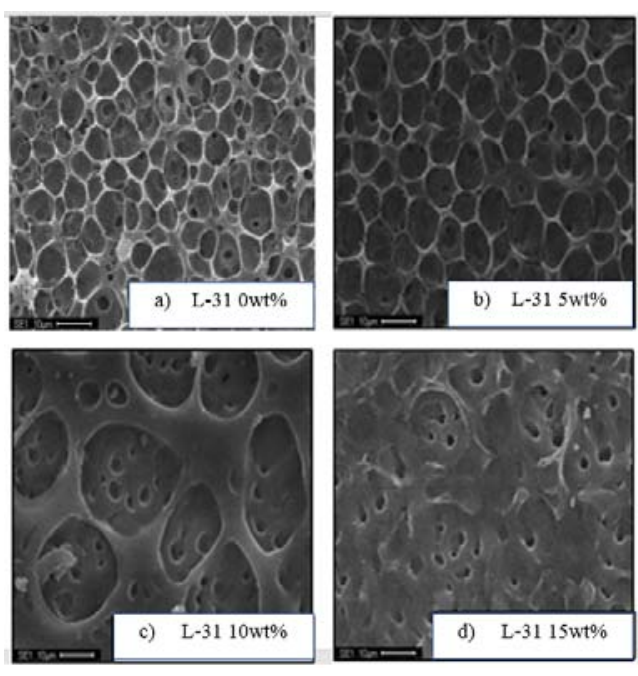

\section{INTRODUCTION}

Polymer disperse liquid crystals (PDLCs) represent an important class of materials for electrooptical device applications. In their most common configuration, PDLC films consist of micrometersized, birefringent liquid crystalline droplets dispersed in a uniform polymer film. Such films have been the subject of interest related to light control applications and electronic displays for the last few decades. ${ }^{1-12}$

In the past many studies have been performed to investigate the morphology and electro-optical properties of PDLC display with variations in mixture compositions, materials and configurations of LCs, monomers and dyes ${ }^{7-10}$ curing conditions such as UV irradiation and temperature. ${ }^{13-17}$ Further, the orientation order of LC materials inside PDLCs with the control of voltage/ composition has been studied. ${ }^{11}$

The results of such studies revealed that the special interactions among the liquid crystals (LCs) with the polymer matrix as well as with the glass substrate, play an essential large role on the PDLC morphology and influence also on the electrooptical properties of PDLC films. ${ }^{1-10,}{ }^{28-33}$ Such types of special interactions on the surfaces and among the molecules are generally known as the anchoring energies. Earlier in the PDLC studies; in order to control the surface anchoring energies, the

\footnotetext{
${ }^{*}$ Corresponding author: yjjeon@konkuk.ac.kr
} 
amphiphilic materials such as the polymers and surfactants were utilized to reduce the surface anchoring interactions. ${ }^{18-19,22}$

Norland Optical Adhesive 65 (NOA65) is a well-known commercial material used in PDLCs studies. ${ }^{23,24}$ It is composed of thiol-ene molecules containing the $\mathrm{SH}_{2}$ - group and multifunctional groups, insuring cross-linking and network formation as well as a photo-initiator. NOA65 is extensively employed as an efficient non-toxic adhesive and in research studies as a network forming system with a high cross-linking density under UV-irradiation. ${ }^{25-27}$ Particularly in PDLC studies, NOA65 is utilized as key material to control the rate of phase separation and related electro-optical and morphological characteristics. ${ }^{19}$

In comparison of the acrylate-based display devices with the thiol-ene system; the thiol-ene provides various useful features, like less light initiator dosage, excellent thermal insulation, inertia to oxidation, high refractive index, and water resistance. ${ }^{20}$

Many researchers in the display field, still considered that there exists an essential gap, which needed to be further explored in terms of the electro optical enhancement of NOA65-E7 composites, even without the chemical modification of polymer mixture. Such goal might be accomplished by optimization of the constituents, concentrations and processing parameters, and possibly by inclusion of few additional components. ${ }^{21}$ For this purpose, we demonstrate that doping of NOA65 with E7, into PDLC films with appropriate Pluronic ${ }^{\circledR}$ materials/ compositions may enhance the electro-optical properties. The objective of the current study is to reduce the surface anchoring of thiol-ene based PDLC films by adding Pluronic $\mathbb{R}$ material.

For this work, different weight ratios of thiolene-Pluronic ${ }^{\circledR}$ were employed while the compositions of liquid crystals were kept unchanged. The impact of insertion of the Pluronic ${ }^{\circledR}$ in thiol-ene based PDLC film was explored via investigating the prepared PDLC films morphology and electrooptical characteristics. Further the impact of variations of Pluronic in glass transition temperature of thiol-ene based polymer matrix were also studied.

\section{EXPERIMENTAL}

\section{Materials}

Here in this work, we adopted a Pluronic ${ }^{\circledR}$ polymeric matrix in thiol-ene system to study the inter-molecular interactions, free volume space via polymer dispersed liquid crystal films (PDLC). Here in the UV curable monomer NOA65 (Norland Products Co., Merck-Korea) has been employed as a thiol-ene monomer.

The Norland Optical Adhesive 65 (NOA65) is a transparent, colorless, liquid photopolymer, when exposed to ultra-violet (UV) light it becomes $100 \%$ solid. NOA65 exhibited the glass transition temperature at $-60^{\circ} \mathrm{C}$ which showed it high rigidity. Further NOA65 has 1.524 refractive index, $1200 \mathrm{cps}$ viscosity and 20000 Modulus of Elasticity (psi). ${ }^{22}$ Here in this polymeric matrix study, a Pluronic $\AA$ polymer L-31 was selected as the second polymer. This Pluronic ${ }^{\circledR}$ polymer is named as L-31 written as $\left(\mathrm{PEO}_{75}-\right.$ $\mathrm{PPO}_{30}-\mathrm{PEO}_{75}$ ) (Sigma-Aldrich chemical). The molecular structure of such material can be seen in Figure 1. It is found as liquid phase. Pluronic ${ }^{\circledR}$ polymer is chemically interesting as it has a flexible molecular structure where hydrophobic PPO blocks and hydrophilic PEO with $10 \%$ of mass ratio with PPO segments are coexisting. Thus, it turns out as a different associative patterns with media on changing the composition and temperature ${ }^{34}$. For this reason, L-31 exhibits mainly hydrophilic character. In order to prepare PDLC films from such polymer materials, a mixture of nematic liquid crystals BL-001 (Merck-Korea) was used. BL001 is mostly considered as equivalent in characteristics to E7 liquid crystal. The LC BL-001 has a composition of $51 \%$ n-pentyl-cyanobiphenyl (5CB), 25\% n-heptylcyanobiphenyl (7CB), 16\% n-octyloxycyanobiphenyl (8OCB), and $8 \%$ n-pentyl-cyanoterphenyl $(5 \mathrm{CT})$ with a nematic to isotropic temperature $\left(\mathrm{T}_{\mathrm{NI}}\right)=61{ }^{\circ} \mathrm{C}$ and contains an ordinary refractive index of 1.5216 .
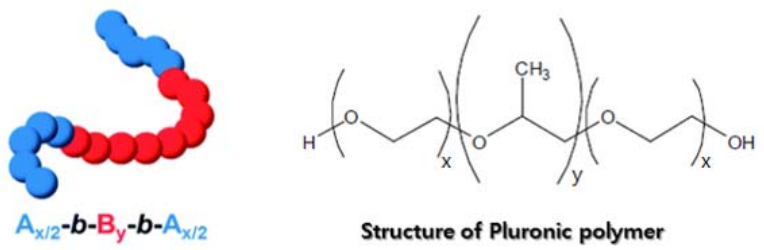

Fig. 1 - Molecular structure of Pluronic ${ }^{\circledR} \mathrm{L}-31\left(\mathrm{PEO}_{75}-\mathrm{PPO}_{30}-\mathrm{PEO}_{75}\right)$.

\section{PDLC film preparation}

The PDLC mixtures consist of four different compositions of L31, NOA65, while the LC BL-001 ratio was kept fixed. The contents of $\mathrm{L} 31$ were varied from $0-15 \mathrm{wt} \%$ (i.e. $0,5,10$ and $15 \mathrm{wt} \%$ ) in $40 \mathrm{wt} \%$ of thiol-ene, while amount of LC was kept fixed as $60 \mathrm{wt} \%$. Different compositions for the PDLC films are mentioned in Table 1. Such compositions were vigorously stirred over night at room temperature conditions to prepare a homogenized isotropic mixture.

In the next step, these mixtures were filled out between two cleaned conductive indium tin oxide (ITO) glass plates. For controlling the film thickness, the micro bead spacer with $20 \mu \mathrm{m}$ of diameter (Sekisui chemicals, Japan) was dispersed over the ITO glass prior to disperse the PDLC mixture. The PDLC devices were prepared by using polymer-induced phase separation (PIPS) method with UV light photo-initiated polymerization technique. Particularly, the PIPS method takes place when a LC is mixed with a solution that has not yet undergone polymerization (a pre-polymer). At the stage, when a homogeneous solution is established, the polymerization reaction is started. As such reaction continues further, the LC molecules come out of solution and start to form droplets ${ }^{28}$. Such PDLC cells were UV cured by irradiation of $365 \mathrm{~nm}$ wavelength $(\lambda)$ of light at room temperature conditions. Upon 
the final fabrication of these PDLC devices various properties were investigated by different analyzing techniques.

\section{Table 1}

The composition of different PDLC preparation

\begin{tabular}{llll}
\hline Preparation & $\begin{array}{l}\text { NOA65 } \\
\text { wt\% }\end{array}$ & $\begin{array}{l}\text { L-31 } \\
\mathbf{w t} \%\end{array}$ & $\begin{array}{l}\text { BL001 } \\
\mathbf{w t} \%\end{array}$ \\
\hline A & 40 & 0 & 60 \\
B & 35 & 5 & 60 \\
C & 30 & 10 & 60 \\
D & 25 & 15 & 60 \\
\hline
\end{tabular}

Experimental measurements

For the evaluation of the inter-molecular interactions, their flexibility, free volume space among the polymer matrix and LC molecules, the conventional and latest techniques were used. At the first step, for the observation of surface morphology of the PDLC films, it was used a polarized optical microscope (POM) (Olympus Model BX-60) at 10X magnification fitted with charge coupling device and a digital camera which was interfaced with computer. In the next step, the electro-optical characteristics were estimated by using the UV-vis spectrophotometer Minolta (Japan) (model UV-3500d) and a voltmeter, which is used to control the voltage. Further to understand the droplet size and extant of phase separation the following devices were observed by SEM, scanning electron microscope (Japan, JOEL Co. JSM5200) at a $1500 \mathrm{x}$ magnification. To investigate the polymer film flexibility, solubility of matrix and free volume space the glass transition temperature $\left(\mathrm{T}_{\mathrm{g}}\right)$ of polymer matrix was measured by differential scanning calorimetry (DSC). For the morphology and the glass transition temperature studies, the PDLC films were dipped in ethanol for 20 hours to remove the liquid crystals. For DSC the purpose $0.03 \mathrm{~g}$ of the PDLC mixture were placed on the DSC stage with adoptive weight ratios of the materials. At this step, the heating rate was increased from $-65^{\circ} \mathrm{C}$ to $65^{\circ} \mathrm{C}$ at $2^{\circ} \mathrm{C} / \mathrm{min}$ rate. Upon kept staying at $65^{\circ} \mathrm{C}$ for 3 minutes, the temperature was then cooled down to $20^{\circ} \mathrm{C}$ with $2^{\circ} \mathrm{C} / \mathrm{min}$ rate. Such procedure was reiterated twice.

\section{RESULTS AND DISCUSSION}

\section{Morphologies}

Initially the thiol-ene with L-31 polymer based PDLCs morphologies were studied by conventional method by employing polarized optical microscopy (POM) at 10x lens magnification with 90 angle of polarizer film at zero applied voltage. The observed PDLC film images can be seen in Figure 2 with respect to variation in percentage ratios contents of $\mathrm{L}-31$ polymer i.e. 0, 5, 10 and $15 \mathrm{wt} \%$. Further the LC contents were kept unaltered in the fabrication of PDLC films i.e $60 \mathrm{wt} \%$. Figure 2(a-d) exhibited two states; dark/colored state under the POM. These two states of the POM images express the random orientation of nematic LCs. ${ }^{27}$

Figure 2(c, d) showed dark/colored images of nematic liquid crystals, possibly owing the largest droplet size. The size of these droplets is in the range of 2 to $10 \mu \mathrm{m}$. Earlier it was considered at azimuthal angle close to $0^{\circ}$ the concentric LC configuration circles were found perpendicular to the bottom polarizer. As a result of it, the droplet exhibited a minimum optical retardation effect and the texture was found as $\operatorname{dim}$ (dark). ${ }^{27} \mathrm{~A}$ deeper insight into Figure 2(c \& d), clarifies that they have characteristic bipolar eye like texture.
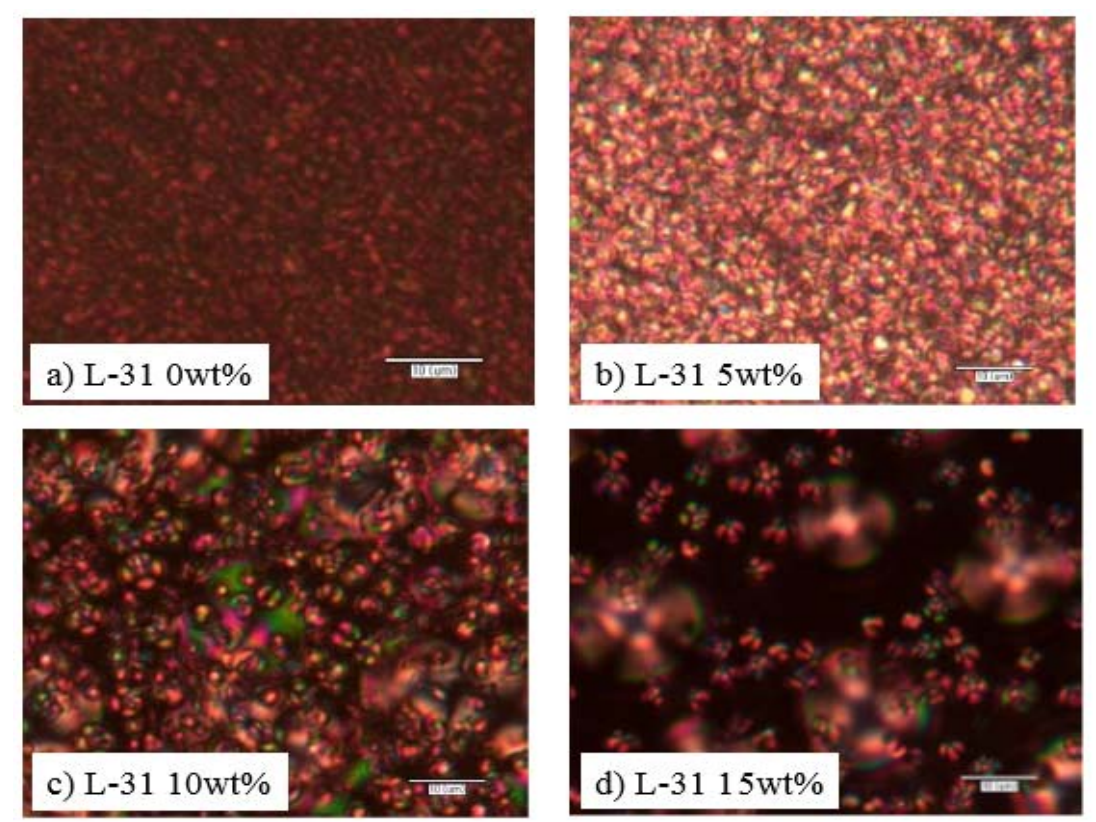

Fig. 2 - The surface morphology of PDLC film as viewed by polarized optical microscope (POM). 

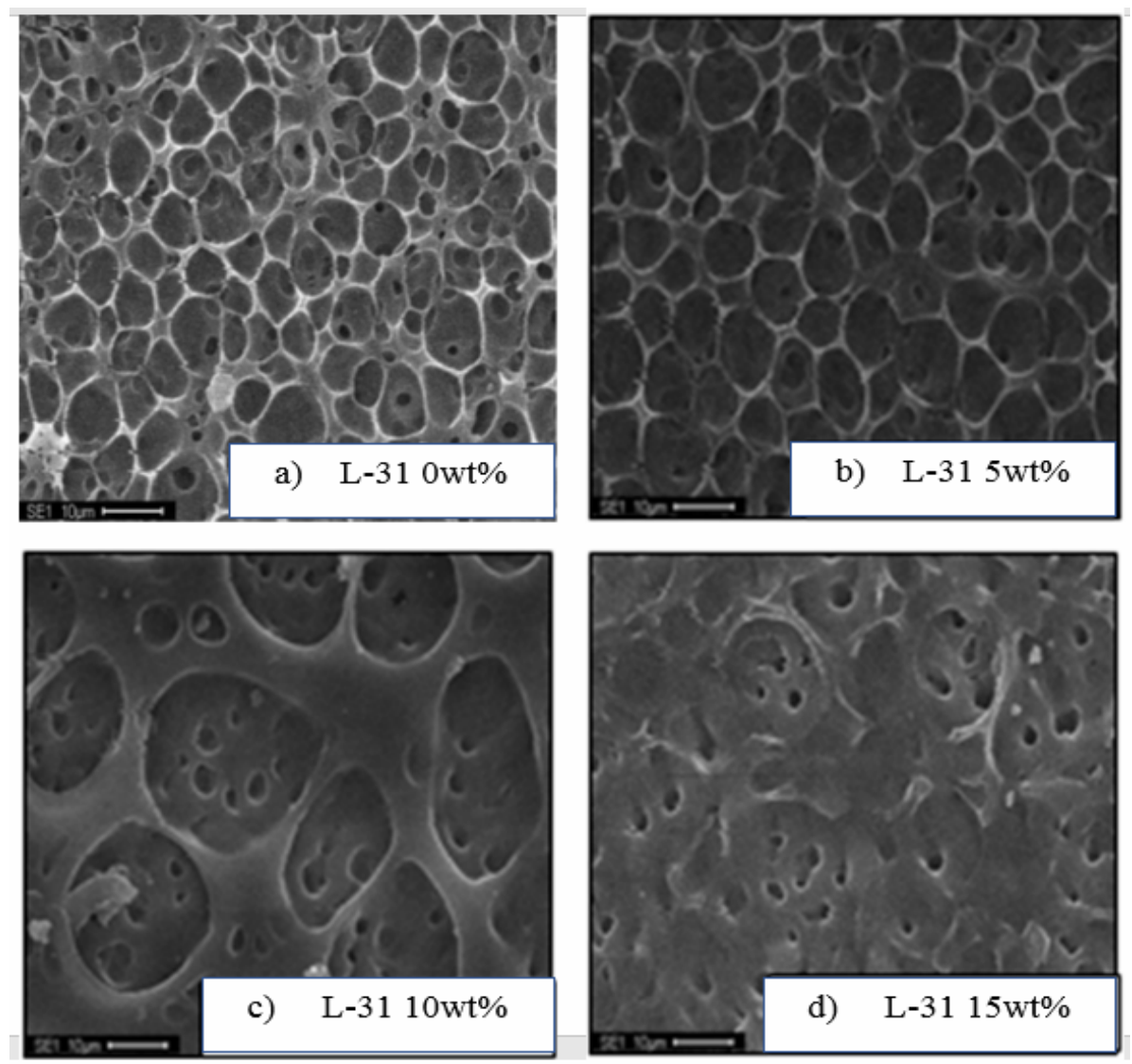

Fig. 3 - The SEM images of the fabricated PDLC films.

In order to further investigate the PDLC films, the SEM analysis was performed. This is performed to understand the effect of variations in thiol-ene/ L-31 weight compositions on droplet formations and sizes. The SEM images may help to know the variations in intermolecular interactions with various compositions in terms of droplet sizes. For this reason, at first the LC molecules were extracted out from the PDLC devices by dipping them in the ethanol/isopropyl 1:1 mixture for 20 hours. In the next step, such films were dried at vacuum $60^{\circ} \mathrm{C}$ temperature to evaporate all remaining solvent. Subsequently, the surface images from SEM technique were taken for all PDLC samples. All such SEM images are presented in Figure 3(a-d).

Figure $3 \mathrm{a}$ displayed the PDLC film prepared from L-31 with $0 \mathrm{wt} \%$. Here the prepared PDLC sample showed droplet morphology having larger sized droplets imbedded in matrix. The droplets were in the size ranges of $2-10 \mu \mathrm{m}$. The thiol-ene reaction utilizes allyl-functionalized monomers to make monomer chains while thiol compounds are crosslinked with each other. ${ }^{2}$ When the L-31 polymer was inserted of 5, 10 and $15 \mathrm{wt} \%$ ratios with thiol-ene compound a variation in droplet size and shape was found (shown in Figure 3b-d).
Interestingly for addition of $5 \mathrm{wt} \%$ ratios of L-31 a small change in droplet size and a regular structure in droplet shape was seen. The following images showed monolayer formation of PDLC films. Further with addition of L-31 (10 wt $\%)$ an average increase in droplet size was observed with little distortion in LC droplets shapes. In addition to this multilayer formation of LCs droplets was also seen in Figure 3(c). A similar multilayer morphology with swiss cheese like structure can be seen for Figure 3(d) at $15 \mathrm{wt} \%$ of L-31. The following morphology showed relatively smaller in sized the LC droplets that remained under the $10 \mu \mathrm{m}$.

The various droplet sizes as viewed by SEM images are shown in Table 2 with the variations in L-31 contents. Previously the variation in droplet morphology indicates the variations in polymerization rate, emulsion composition, flexibility and in inter molecular interactions of following matrix as other conditions were kept fixed. The alterations in morphology bring changes in electro-optical behavior for the prepared PDLC films. Hence, such study was crucial to explore the key factors behind the variations in morphology and electro-optical characteristics related to each other. 
Table 2

Droplet sizes of PDLC morphology as measured by SEM

\begin{tabular}{c|c}
\hline $\begin{array}{c}\text { Pluronic }{ }^{\circledR} \text { contents } \\
(\mathbf{w t} \%)\end{array}$ & Average droplet size $(\mu \mathrm{m})$ \\
\hline 0 & 6.5 \\
5 & 5.2 \\
10 & 9.3 \\
15 & 7.6 \\
\hline
\end{tabular}

\section{Electro optical properties}

Morphological studies explain the variations in droplet morphology as mainly directed by variations in PDLC emulsion compositions, intermolecular interactions, free volume space and degree of phase separation. Whereas the electrooptical properties of PDLC films are controlled by PDLC morphologies. The electro-optical (EO) characteristics of the prepared PDLC films were calculated and plotted in Figure 4. For the different applied voltages, the percent transmittance of incident light at zero angle through PDLC devices was estimated via UV-visible spectrophotometer.

Here, Figure 4 exhibited that transmittance- and contrast ratio (CR) curves against voltages increased with various trends. A close look into the Figure 4a shows the transmittance vs voltage curves, which increases with applied voltages. The plotted curves with distinguished slopes indicated the dependency of EO properties on PDLC composition. The diverse association behavior of Pluronic ${ }^{\circledR}$ polymer with the polymer matrix and LC that turned into diverse droplet morphologies. Figure 4a presented a decrease in off scattering of PDLC device that is fabricated with emulsion having $5 \mathrm{wt} \%$ \& $10 \mathrm{wt} \%$ of L-31 as compared to $0 \mathrm{wt} \%$ of $\mathrm{L}-31$. Other samples showed that device fabricated with $15 \mathrm{wt} \%$ of following L-31 a decrease in off scattering has been observed. Whereas, ON transmittance seems independent of emulsions compositions or showed minor impact on this property. For the fabricated PDLC films, the contrast ratio (CR) was calculated as $\mathrm{CR}=\mathrm{T}_{\mathrm{ON}} / \mathrm{T}_{\mathrm{OFF}}$, and presented in Figure $4 \mathrm{~b}$, that enlighten the importance of utilized material. It is observed from Figure $4 \mathrm{~b}$, that CR of the PDLC film fabricated with 0 wt $\%$ of L-31 mixture have the highest contrast ratio i.e., $2.04 \mathrm{CR}$ at 15 volts. Further it crossed the highest level 3.2 CR at 30 volts. However, the $\mathrm{CR}$ for $5 \mathrm{wt} \%$ \& $10 \mathrm{wt} \%$ were decreased and shown in Figure $4 \mathrm{~b}$. Whereas, the PDLC device fabricated with $15 \mathrm{wt} \% \mathrm{~L}-31$ indicated contrast ratio 3.4 at max volts. This behavior explained the importance of Pluronic ${ }^{\circledR}$ in thiol-ene studies to make optimal properties of PDLC device. The plots for the threshold voltages $\left(\mathrm{V}_{\text {th }}\right)$ and saturation voltages $\left(\mathrm{V}_{\text {sat }}\right)$ calculated from the following charts are presented in the Figure 5(a,b).
$\mathrm{V}_{\text {th }}$ and $\mathrm{V}_{\text {sat }}$ are estimated with insertion of linear trend lines on the volt-transmittance data and crossing the two lines at maximum intersecting slopes which are presented in the Figure 5a. Here Figure $5 \mathrm{~b}$ showed a decreasing trend for $\mathrm{V}_{\text {th }}$ and increasing trend for $\mathrm{V}_{\text {sat }}$ that was found with the increase in ratios of L-31 in thiol-ene mixture. This emphasis the insertion of external L-31 group in the thiol-ene based PDLC devices that may enhance the flexibility of polymer matrix with increase in droplet morphology which tend to exhibit the transparent state at less minimum voltage.

\section{Glass transition temperature of PDLC film}

In the recent past decades, the study of glass transition temperature $\left(\mathrm{T}_{\mathrm{g}}\right)$, and nematic to isotropic temperature $\left(\mathrm{T}_{\mathrm{NI}}\right)$ has been found as a useful analytical tool in PDLCs to learn the flexibility, mix-ability and free volume space among the polymer and the LCs materials during phase separation. ${ }^{22}$ The basic objective of the current study is to examine the inter-molecular interactions among the polymer and liquid crystal materials. Hence, subsequent results assist the phenomena behind the variations in droplet sizes and electro-optical properties. The glass transition temperature for polymer matrix formed with L-31 and NOA65 at various compositions has been determined by DSC technique. Initially the PDLC cells were immersed in ethanol for 20 hours to remove the liquid crystals from the droplets. DSC was run from $-65^{\circ} \mathrm{C}$ to $65^{\circ} \mathrm{C}$ twice. Further details about the procedure are mentioned in Experimental Measurements section. Earlier, $\mathrm{T}_{\mathrm{g}}$ of NOA65 was found as $-60^{\circ} \mathrm{C}$ when tested alone. ${ }^{13}$ In following studies, the $\mathrm{T}_{\mathrm{g}}$ of polymer film of PDLC that is made up of L-31 (0 wt\%), NOA65 (40 wt\%) and LC $(60 \mathrm{wt} \%)$ was observed as $-9.86{ }^{\circ} \mathrm{C}$. NOA65 is familiar due to its extensively network forming characteristics, high cross-linking density and hard polymer film formation after UV curing. Hence, following $T_{g}$ results revealed the increase in flexibility of polymer film due to alteration of solubility of polymer matrix with the liquid crystal molecules. ${ }^{22-24}$ Furthermore, the results on addition of L-31 from $5 \mathrm{wt} \%-15 \mathrm{wt} \%$ are shown in Table 3. It was observed from Table 3 that with addition of $5 \mathrm{wt} \%$ of $\mathrm{L}-31$ the $\mathrm{T}_{\mathrm{g}}$ further increased to $-7.54^{\circ} \mathrm{C}$. Then, on further addition of L-31 showed further decrease in $\mathrm{T}_{\mathrm{g}}$ from $-26.37^{\circ} \mathrm{C}$ to $-28.41^{\circ} \mathrm{C}$. Current findings revealed that initially with insertion of small amount of L-31 the intermolecular interactions of polymer film slightly changed thus a slight increase in $T_{g}$ is observed. However, with 
further increase in L-31 (5 wt $\%-10 \mathrm{wt} \%)$ the $\mathrm{T}_{\mathrm{g}}$ decreases from $-7.54{ }^{\circ} \mathrm{C}$ to $-26.37{ }^{\circ} \mathrm{C}$, which highlight a decrease in intermolecular forces. On further insertion of L-31 (10wt $\%-15 \mathrm{wt} \%)$ a small decrease in $\mathrm{T}_{\mathrm{g}}$ is observed. From these findings one can deduce that overall a decrease in intermolecular attractions are observed with insertion of L-31. Thus, the droplet size showed an average increasing trend with insertion of L-31. A deep analysis of SEM morphology revealed mainly monolayer formation of PDLC morphology at

$\rightarrow$ L31 (0 wt\%) $\rightarrow$ L31 (5wt\%) - L31 (10wt\%) - L31 (15wt\%)

a

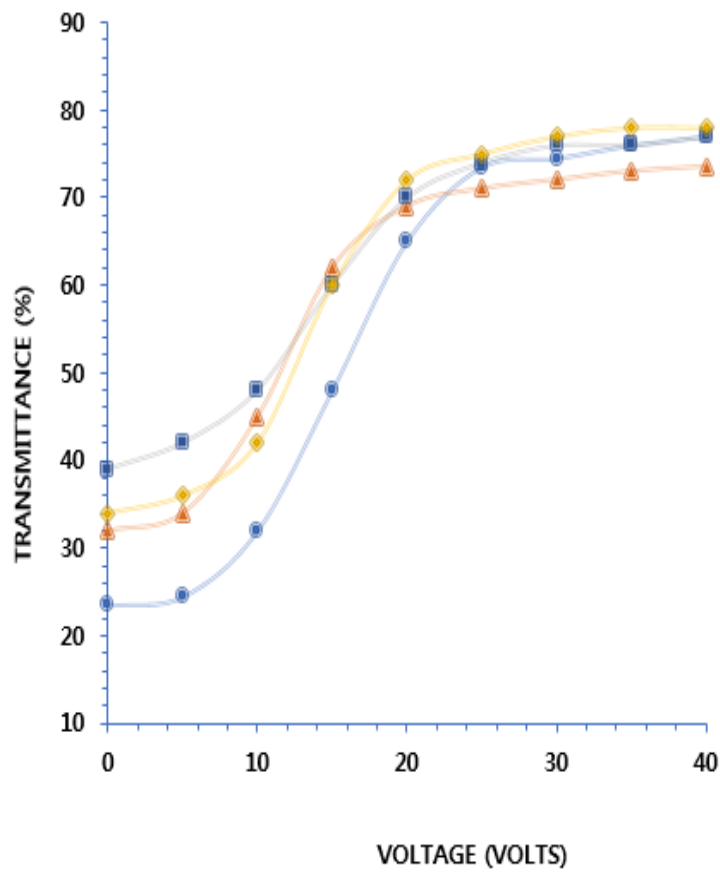

$5 \mathrm{wt} \%$ of L-31, while on increase of L-31 an increase in droplet size with multilayer formation of polymer layer was observed. This may attribute to the increase in free volume space that enhance the cross-linking density of NOA65. This showed a reduction in the unbending nature of polymer network which is clear from $\mathrm{T}_{\mathrm{g}}$ and morphology discoveries. Consequently, the following polymeric material (Pluronic $\AA$ ) can be used for solubility regulator, flexibility control and alteration of glass transition temperature in PDLCs.
- L31 (0 wt\%) - L31 (5wt\%) - L31 (10wt\%) - L31 (15wt\%)

b

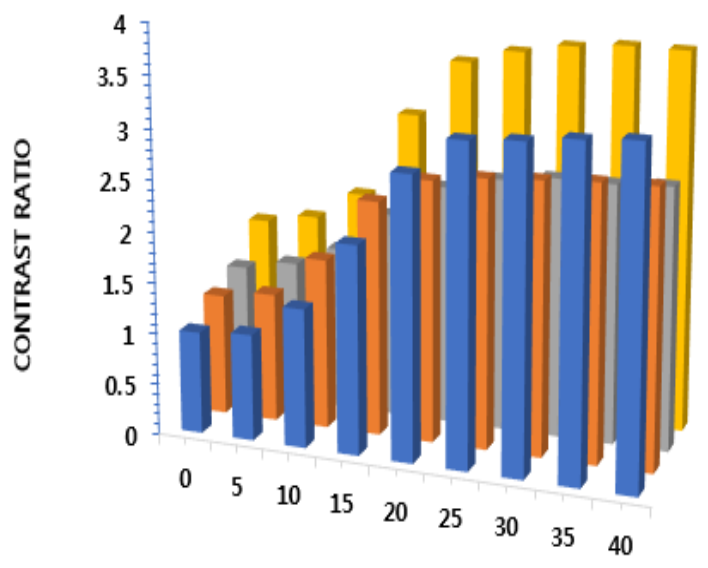

VOLTAGE (VOLTS)

Fig. 4 -A view of the electro optical properties of PDLC prepared films.

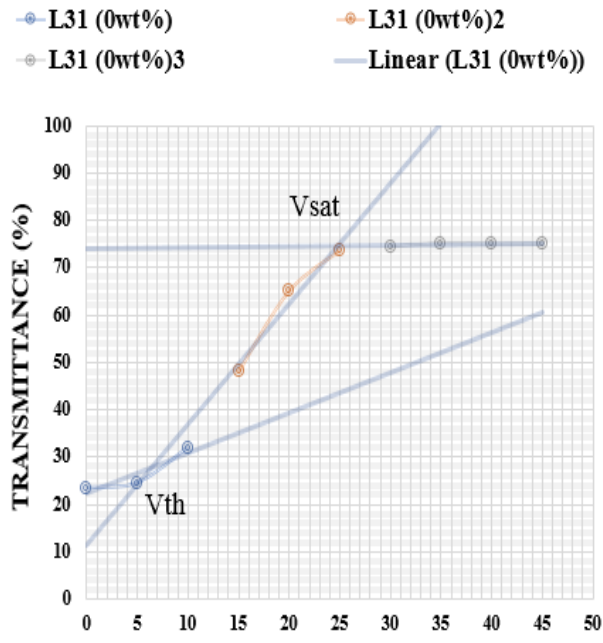

a VOLTAGE (VOLTS)

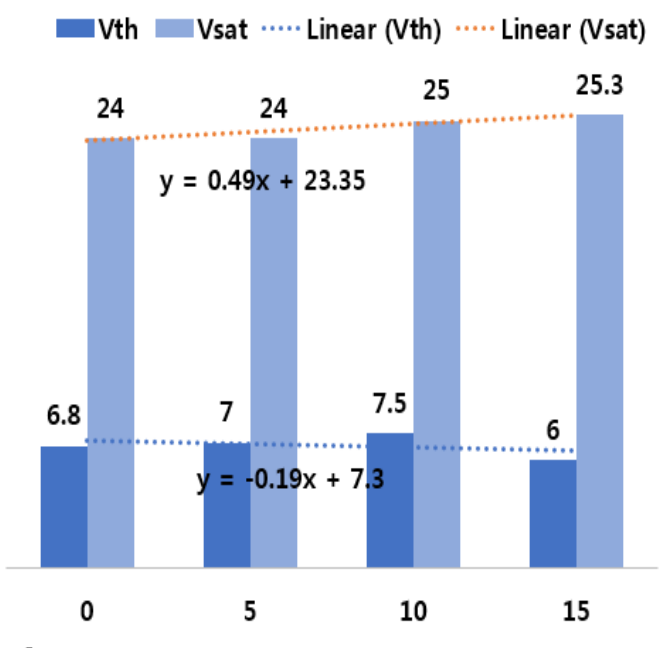

b

VOLTAGE (VOLTS)

Fig. 5 - Threshold voltage and saturation voltage of PDLC. 
Table 3

Glass transition temperature of L31 with various weight percent compositions

\begin{tabular}{l|l|l}
\hline Polymers & Weight percent & $\mathbf{T}_{\mathbf{g}}$ \\
\hline NOA65 & $100 \%$ & $-60^{\circ} \mathrm{C}$ \\
\hline \multirow{2}{*}{ L31 wt\% } & 0 & $-9.86^{\circ} \mathrm{C}$ \\
& 5 & $-7.54^{\circ} \mathrm{C}$ \\
& 10 & $-26.37^{\circ} \mathrm{C}$ \\
& 15 & $-28.41^{\circ} \mathrm{C}$ \\
\hline
\end{tabular}

\section{CONCLUSIONS}

In the current work, the PDLC films were fabricated with thiol-ene polymer matrix, which is well known as NOA65. Such PDLC films are generally formed with highly rigid polymer matrix under UV light and exhibit high $\mathrm{V}_{\text {th }}$ and $\mathrm{V}_{\text {sat }}$ values. In order to overcome such difficulties, L-31 polymer has been introduced in the PDLC mixture with different weight ratios to improve the electrooptical properties by controlling the intermolecular interactions and film flexibility. Our findings conclude that the insertion of L-31 in NOA65/BL001 PDLC system control over crosslinking and formation of high polymer density property by altering the intermolecular interactions. This is clarified by the SEM images that showed an increase in droplet size with insertion of L-31. Moreover, our results revealed that both Contrast ratio and electro-optical properties of the PDLC films are also enhanced with addition of L-31. However, it showed monolayer to multilayer formation of PDLC films with increase in L-31. Following results are confirmed by DSC. Thus, the materials such like L-31 can be used in PDLCs for broad spectrum applications.

Acknowledgements: This paper was supported by Konkuk University in 2016

\section{REFERENCES}

1. P. S. Drzaic, J. Appl. Phys., 1986, 60, 2142.

2. P. S. Drzaic, "Liquid crystal dispersions", World Scientific, Singapore, Vol. 1, 1995, p. 1-338.

3. J. W. Doane, "Liquid Crystals: Applications and Uses", World Scientific, Singapore, Vol. 1, 1990, p.1-361.
4. Y. J. Jeon, Y. Bingzhu, J. T. Rhee, D. L. Cheung and M. Jamil, Macromol. Theory Simul., 2007, 16, 643.

5. Y. J. Jeon, G. H. Lee, J. E. Jang, K. Y. Hwang, F. Ahmad, M. Jamil, J. W. Lee and J. E. Jung, Liq. Crys., 2012, 39, 1314.

6. F. Ahmad, M. Jamil, Y. J. Jeon, J. W. Lee, J. E. Jung, and J. E Jang, Bull. Mater. Sci., 2012, 35, 221.

7. F. Ahmad, J. W. Lee, Y. J. Jeon, M. Jamil, J. Optoelectron. Adv. M., 2017, 19, 309.

8. F. Ahmad, M. Jamil, J. W. Lee, K. N. Lee and Y. J. Jeon, J. Mod. Optics., 2017, 64, 2179.

9. J. W. Lee, J. K. Kim, F. Ahmad, M. Jamil and Y. J. Jeon, Liq. Crys., 2014, 41, 1109.

10. F. Ahmad, M. Jamil, Y. J. Jeon, L. J. Woo, J. E. Jung, J. E. Jang, G. H. Lee and J. Park, J. App. Poly. Sci., 2011, 121,1424 .

11. F. Ahmad, M. Jamil and Y. J. Jeon, J. Disp. Sci. Techno., 2018, 39, 1115-1120.

12. F. Ahmad, M. Jamil and Y. J. Jeon, Arab. J. Chem., 2017, S339.

13. F. Ahmad, M. Jamil, J. W. Lee, S. R. Kim and Y. J. Jeon, Electron. Mater. Lett., 2016, 12, 685.

14. F. Ahmad, J. W. Lee, Y. J. Jeon and M. Jamil, Rev. Roum. Chim., 2017, 62, 907.

15. J. He, B. Yan, B. Yu, S. Wang, Y. Zeng and Y. Wang, Eur. Polym. J., 2007, 43, 2745.

16. H. L. Lui, H-T. Liu and F.-R. Tsai, Poly. Internl., 1997, 42,385 .

17. F. Ahmad, J. W. Lee, Y. J. Jeon and M Jamil, J. Optoelectron. Adv. M. Rap Comm., 2017, 11, 603-607.

18. F. Ahmad, M. Jamil and Y. J. Jeon, Arab. J. Chem., 2017, S339.

19. F. Ahmad, M. Jamil, J. W. Lee, G. N. Jang and Y. J. Jeon, Liq. Crys., 2016, 43, 162.

20. Y. Sun, Y. Gao, L. Zhou et al., Molecules, 2017, 22, 317.

21. O. Yaroshchuk, F. Elouali and U. Maschke, Opt. Mater. (Amst)., 2010, 32, 982-989.

22. J. Lanzo, F. P. Nicoletta, G. De Filpo and G. Chidichimo, J. App. Phys., 2002, 92, 4271.

23. R-D. Benmouna and B-N. Benyoucef, J. Appl. Polym. Sci., 2008, 108, 4072.

24. T. Kyu and D. Nwabunma, Macromolecules, 2001, 34, 9172.

25. G. W. Smith, Phys. Rev. Lett., 1993, 70, 198.

26. R. Bhargava, S. Q. Wang and J. L. Koenig, Macromolecules, 1999, 32, 8982 .

27. R. R. Guimarães, R. S. Mendes, P. R. G. Fernandes and H. Mukai, J. Phys. Condens. Matter., 2013, 25, 404203.

28. M. Mucha, Prog. Polym. Sci., 2003, $28,837$.

29. Y. Zhang, J. Yang, L. Zhou, Y. Gao, M. Hai, L. Zhang, F. Li, G. Zhou, X. Li, C. Zhang, Z. Yang, S. Zhu and H. Yang, Liq. Cryst., 2018, 45, 1068.

30. F. P. Nicoletta, D. G. Filpo, D. Cupelli, M. Macchione and G. Chidichimo, Appl. Phys. Lett., 2001, 79, 4325.

31. F. Liu, H. Cao, Q. Mao, P. Song and H. Yang, Liq. Cryst., 2012, 39, 419.

32. V. Sharma, P. Kumar, C. M. Praveen and K. K. Raina, AIP Confer. Proc., 2018, 1953, 100033.

33. P. Kumar, V. Sharma, C. Jaggi, P. Malik and K. K. Raina, Liq. Cryst., 2017, 44, 843.

34. S. Senkow, S. K. Mehta, D. Douhe'ret, A. H. Roux and G. Roux-Desgranges, Phys. Chem. Chem. Phys., 2002, 4, 4472 . 
